\title{
Continuing discrepancy between patient perception of asthma control and real-world symptoms: a quantitative online survey of 1,083 adults with asthma from the UK
}

\author{
*Monica Fletcher', David Hiles ${ }^{2}$ \\ Education for Health, Warwick, UK \\ 2 Asthma UK, London, UK
}

Originally received 25th April 2013; resubmitted 23rd July 2013; revised 4th September 2013; accepted 13th September 2013; online 11 th November 2013

\begin{abstract}
Background: Previous studies have identified a discrepancy between patient perception of asthma control and real-world symptoms; despite several hypotheses, the reasons remain unclear.

Aims: To explore patients' experiences of asthma symptoms and disease management and their educational needs in the UK; to assess recent progress in asthma control and management.

Methods: A quantitative questionnaire-based online survey of UK patients aged $\geq 18$ years with self-reported asthma.

Results: Of the 1,083 individuals (55\% female, $49 \%$ aged $\geq 55$ years) who completed the survey, $79 \%$ described their asthma control as 'good' or 'very good'. Despite this, in the previous 2 years, $65 \%$ had experienced 'frequent' day-time symptoms, 37\% had 'frequent' night-time symptoms, and $25 \%$ had used oral steroids for asthma; $41 \%$ of those prescribed a reliever inhaler used it $\geq 1$ a day. Overall, $76 \%$ had a 'good' or 'very good' relationship with their healthcare professional (HCP); $32 \%$ had not attended regular asthma reviews and only $12 \%$ were using a personal asthma action plan. Moreover, $70 \%$ of respondents felt that they had the 'main responsibility' for managing their asthma; $29 \%$ believed this responsibility to be shared with their HCP.

Conclusions: This survey indicates a continuing discrepancy between patient perception of asthma control and real-world symptoms, with little change from previous studies. Many patients accept symptoms as the norm. The diversity among respondents' attitudes demonstrates a need to help patients change some of their beliefs and understanding about asthma, and to improve asthma management with better education about the understanding of control for patients and HCPS.

(C) 2013 Primary Care Respiratory Society UK. All rights reserved.

M Fletcher et al. Prim Care Respir J 2013; 22(4): 431-438

http://dx.doi.org/10.4104/pcrj.2013.00091
\end{abstract}

Keywords action plan, asthma, management, nurse, primary care, survey

\section{Introduction}

Asthma is one of the most common chronic conditions, affecting approximately 30 million people in Europe ${ }^{1-3}$ and over 5 million patients in the UK. ${ }^{4}$ Asthma represents a significant health burden, costing the UK National Health Service around $f 1$ billion per year. ${ }^{5,6}$

Poor asthma control is associated with an impaired healthrelated quality of life, lost productivity, emergency hospital

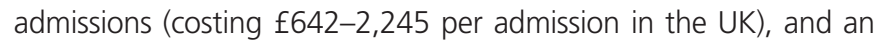
increased risk of exacerbations and death., 5,-11 The British Thoracic Society/Scottish Intercollegiate Guidelines Network (BTS/SIGN) guideline on the management of asthma ${ }^{12}$ indicates that treatment should be based on disease severity. Other influential guidelines, such as those from the Global Initiative for Asthma (GINA), emphasise control. Asthma control encompasses the patient's recent clinical state (symptoms, night-time awakening, reliever inhaler use, lung function), ability to carry out usual daily activities, and exacerbation risk..$^{13}$ The BTS/SIGN guidelines base asthma control on the healthcare professional (HCP)'s clinical judgement and the patient's recent symptoms, which can be assessed using tools such as the Asthma Control Questionnaire (ACQ), the Royal College of Physicians (RCP) '3 Questions', or the Asthma Control Test (ACT). ${ }^{12}$

Based on current definitions of asthma control, real-world asthma control remains poor. ${ }^{14,15}$ In a recent European study, approximately half of all UK patients had asthma that was not well

\footnotetext{
* Corresponding author: Ms Monica Fletcher, Education for Health, The Athenaeum, 10 Church Street, Warwick CV34 4AB, UK.

Tel: +44 (0)1926 493313 Fax: +44 (0)1926 493224 E-mail: m.fletcher@educationforhealth.org
} 
controlled. ${ }^{14}$ Other studies have also consistently reported a tendency for both HCPs and patients to overestimate the level of asthma control achieved. ${ }^{5,7,16-21}$ Indeed, many patients consider their asthma to be controlled despite experiencing severe symptoms. ${ }^{18}$

Several reasons have been suggested for the discrepancy between real-world asthma control and patient or HCP perceptions. ${ }^{5,7,16-21}$ Possible factors relating to patients include poor medication adherence and low expectations of symptom control; 17,20,22 for HCPs, influential factors include a lack of awareness or implementation of guidelines, undertreatment with inhaled corticosteroids, and failure to recognise frequent reliever inhaler use as an indication of poor control. ${ }^{19,23}$ Communication difficulties between patients and HCPs also affect control, and studies have identified discrepancies between patients' expectations and their experiences with HCPs. ${ }^{17,20}$ In one study almost $20 \%$ of patients had not discussed their asthma with an HCP. ${ }^{20}$ Indeed, improved education and more time to develop a partnership between HCPs and patients are recognised as being central to asthma management. ${ }^{24}$

This survey of over 1,000 patients in the UK explored levels of asthma symptoms and their impact on patients' lives, individuals' experiences of asthma and its management, and current educational needs. Our findings provide a timely assessment of whether asthma control and management have changed in recent years.

\section{Methods}

\section{Study design}

This quantitative online survey was designed to assess patients' attitudes to, and experiences of, asthma and its management in a real-world setting. A market research questionnaire was developed to collect data directly reported by respondents. In line with the 2012 Legal and Ethical Guidelines for Healthcare Market Research (British Healthcare Business Intelligence Association), ${ }^{25}$ research ethics committee approval was not required. The survey was carried out in accordance with the Codes of Conduct of the Market Research Society, the European Pharmaceutical Marketing Research Association, the Association of the British Pharmaceutical Industry, and the Data Protection Act (UK, 1998).

\section{Questionnaire development}

The authors, in collaboration with Insight Research Group (London, UK), developed the questionnaire through an iterative process of consultations with asthma experts, including HCPs and patient organisations. Questionnaire wording and length and the suitability of pre-codes were assessed in telephone interviews with two patients.

For questions relating to day-time or night-time symptoms, steroid use, Accident and Emergency department (A\&E) visits and discussions of symptoms with HCPs, respondents were asked to recall their experiences over the previous two years. This period was chosen to allow accurate memory recall and to capture a representative average of symptoms, including rare events.

\section{Study population}

The online survey was conducted in November 2011 by YouGov. An e-mail was sent to 5,563 adults (aged $\geq 18$ years) of the UK public
Table 1. Demographic characteristics of respondents

Respondents $(n=1,083)$

\begin{tabular}{ll}
\hline Female & $55(592)$ \\
\hline Ethnicity & \\
White British & $90(977)$ \\
Other white & $4(45)$ \\
Other & $5(59)$ \\
Not answered & $0(2)$ \\
\hline Age range & \\
18-34 years & $20(218)$ \\
$35-54$ years & $31(333)$ \\
$\geq 55$ years & $49(532)$ \\
\hline Work status at the time of the survey & \\
In work & $51(552)$ \\
Retired & $30(320)$ \\
Other & $19(211)$ \\
\hline Asthma medication & \\
Preventer inhaler and reliever inhaler & $64(697)$ \\
Reliever inhaler only & $17(184)$ \\
Combined inhaler & $12(126)$ \\
Preventer inhaler only & $5(51)$ \\
Other & $2(25)$ \\
\hline
\end{tabular}

Values are given as \% (n).

who had identified themselves as having asthma when they enrolled in the YouGov panel and who declared an intention to complete online surveys. In the current survey, respondents were asked to confirm that they had been diagnosed with asthma and were currently receiving treatment; only respondents who affirmed were invited to complete the survey.

\section{Data analysis}

Questionnaire responses were collated by YouGov and provided to Insight Research Group for analysis in line with the survey protocol. Descriptive statistics (mean, median, and standard deviation) were calculated.

\section{Results}

\section{Respondent population}

Overall, 5,563 individuals who had previously stated that they had asthma represented the pool of potentially eligible participants. In all, 1,083 respondents (19\%) confirmed that they had been diagnosed with asthma and were currently receiving asthma medications, and completed the survey (Table 1); this response rate is consistent with that typically observed by YouGov for similar surveys.

\section{Respondent-reported real-world asthma symptoms}

Overall, $65 \%$ of respondents $(n=702)$ had experienced frequent ('sometimes', 'often' or 'every day') day-time asthma symptoms and $37 \%(n=398)$ had experienced frequent night-time symptoms in the past 2 years (Figure 1). The most common day-time symptoms were wheezing, coughing, and breathlessness (Table 2). Moreover, 12\% of respondents $(n=135)$ had visited $A \& E$ and $25 \%(n=274)$ had used oral steroids, both owing to asthma, in the previous two years. Of the 881 respondents prescribed a reliever inhaler, $41 \%$ used it 

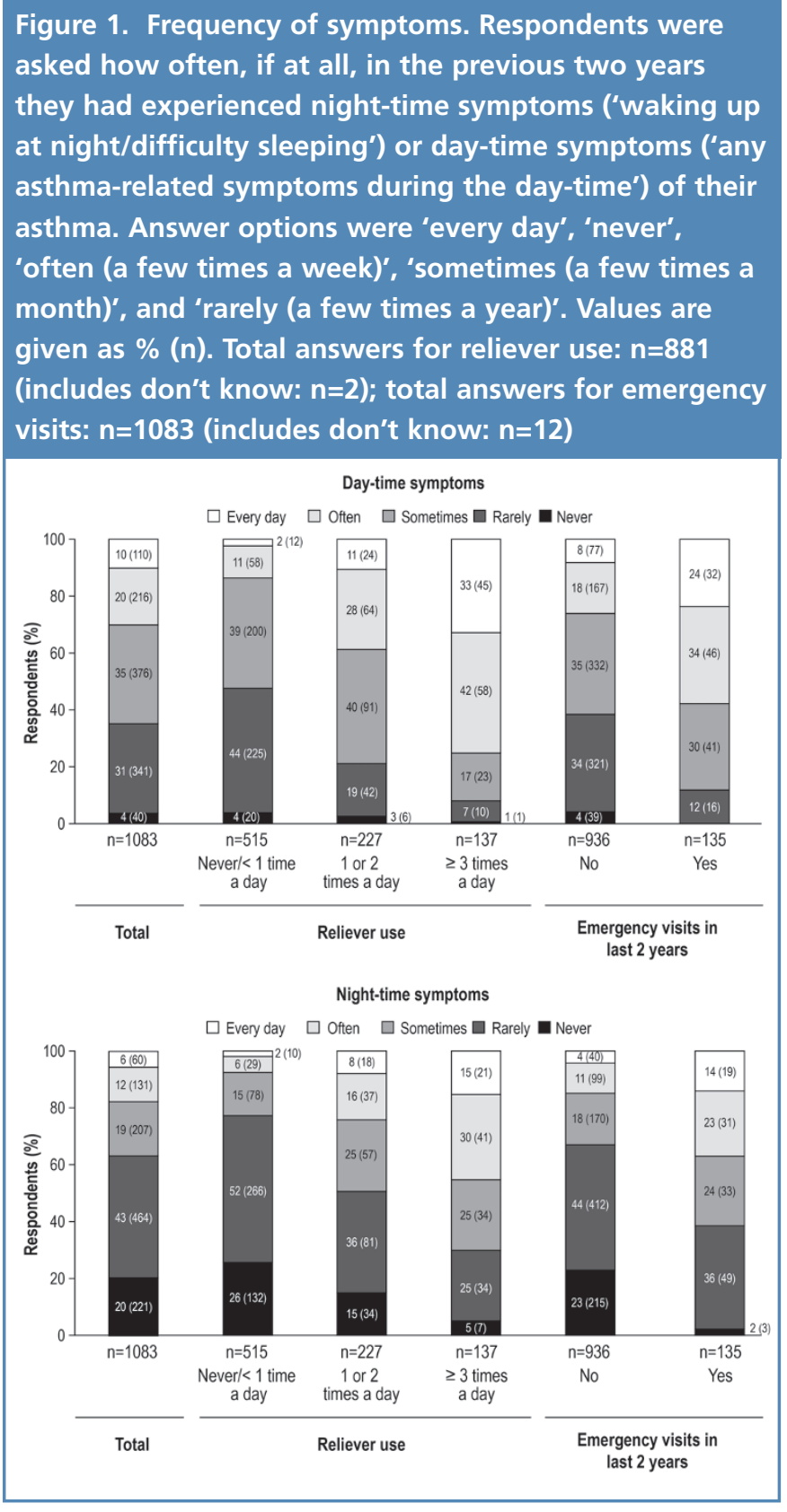

Figure 2. Frequency of reliever medication use. Base: those prescribed reliever or reliever and preventer medication ( $n=881$; includes 'don't know': $n=2$ ). Values are given as $\%(n)$

or 2 times a day

regularly (at least once a day; Figure 2).

When asked about the impact of asthma on their life, respondents most commonly selected: being unable to go out in cold weather $(27 \%, n=293)$, participating in sport or hobbies as much as they would like $(24 \%, n=264)$, and being unable to go out in hot or humid weather as much as they would like $(17 \%, n=179)$.

\section{Respondents' understanding and perception of} asthma control

Respondents' understanding of the term 'asthma control' varied markedly. The majority thought that 'good asthma control' meant being able to do all the daily activities that they want to $(70 \%$, $n=763)$, breathing without problems $(68 \%, n=736)$, and using their reliever inhaler less $(59 \%, n=642)$. Approximately half of respondents considered 'good asthma control' to mean not having trouble sleeping $(49 \%, n=532)$ and being able to exercise or take part in sport $(47 \%, n=508)$. 'Having none of the normal asthma symptoms' (as interpreted by respondents) was selected as a definition for 'good asthma control' by only $40 \%$ of respondents $(n=436)$, and $33 \%$ ( $n=362)$ chose 'having no symptoms'.

The majority of respondents thought that their asthma was controlled even if they had 'frequent' symptoms or regularly used their reliever inhaler (Table 3). Overall, $79 \%$ of respondents $(n=859)$

Table 2. Frequency of specific day-time symptoms

\begin{tabular}{|c|c|c|c|c|c|}
\hline & Base* & Ever experienced & Every day/often & Sometimes/rarely & Never \\
\hline Coughing & 1,039 & $93(969)$ & $34(354)$ & $59(615)$ & $7(70)$ \\
\hline Tiredness & 1,018 & $83(847)$ & $40(411)$ & $43(436)$ & $17(171)$ \\
\hline Tight chest/chest pain & 1,034 & $81(833)$ & $15(157)$ & $65(676)$ & $19(201)$ \\
\hline Difficulty eating & 1,028 & $34(353)$ & $6(57)$ & $29(296)$ & $66(675)$ \\
\hline
\end{tabular}


Table 3. Perceived levels of control and satisfaction with control level by symptoms and respondent understanding of 'good asthma control'

\begin{tabular}{|c|c|c|c|c|c|c|c|c|c|c|}
\hline & \multirow{2}{*}{ 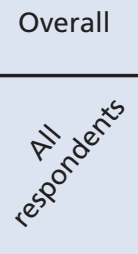 } & \multicolumn{3}{|c|}{ Reliever use } & \multicolumn{2}{|c|}{$\begin{array}{c}\text { Emergency } \\
\text { department visits }\end{array}$} & \multicolumn{2}{|c|}{$\begin{array}{l}\text { Day-time } \\
\text { symptoms }\end{array}$} & \multicolumn{2}{|c|}{$\begin{array}{l}\text { Night-time } \\
\text { symptoms }\end{array}$} \\
\hline & & $\hat{i}^{\hat{e}^{2}}$ & $\mid \begin{array}{l}0^{2} \sigma^{0} \\
0^{0} e^{2} \\
\sum^{2}\end{array}$ & $\begin{array}{l}e^{y} \\
x^{5} \\
3^{2}\end{array}$ & $\alpha^{e^{e}}$ & $\mathrm{r}^{0}$ & $e^{e^{e^{2}}}$ & $e^{e^{2}}$ & $5^{e^{e^{2}}}$ & $e^{e^{a^{2}}}$ \\
\hline \multicolumn{11}{|c|}{ Overall, how would you describe the control you generally have over your asthma? } \\
\hline Very good/good, \% & 79 & 89 & 75 & 52 & 59 & 83 & 94 & 71 & 89 & 63 \\
\hline Average, \% & 18 & 11 & 22 & 38 & 34 & 15 & 5 & 25 & 9 & 33 \\
\hline Poor/very poor, \% & 3 & 1 & 3 & 9 & 7 & 2 & 1 & 4 & 2 & 5 \\
\hline \multicolumn{11}{|c|}{ And how satisfied or unsatisfied would you say you are with the level of control you currently have over your asthma? } \\
\hline Respondents & $\mathrm{N}=1,083$ & $n=515$ & $n=227$ & $\mathrm{n}=137$ & $n=135$ & $n=936$ & $n=381$ & $n=702$ & $\mathrm{n}=685$ & $n=398$ \\
\hline Very unsatisfied, \% & 1 & 0 & 1 & 4 & 5 & 0 & 0 & 1 & 0 & 2 \\
\hline
\end{tabular}

described their asthma control as 'very good' or 'good'. However, $28 \%(n=241)$ of these respondents used their reliever inhaler at least once a day, $8 \%(n=71)$ used it at least three times a day, and $58 \%$ $(n=500)$ had frequent day-time symptoms. Similarly, although $91 \%$ of respondents ( $n=986)$ were satisfied with their asthma control, $31 \%(n=305)$ of these used their reliever inhaler at least once a day.

Of the 854 respondents who had ever had uncontrolled asthma, $76 \%$ were confident in managing their symptoms after a loss of control. Only $19 \%$ were either 'not very confident' (16\%) or 'not at all confident' (3\%) in managing uncontrolled asthma; $5 \%$ of respondents selected 'don't know'.

The majority of respondents ( $59 \%, n=640$ ) considered that it was not possible to improve their asthma control. This attitude was more prevalent among those with infrequent day-time symptoms than those with frequent day-time symptoms $(72 \%, n=274)$ vs. $52 \%, n=366)$. Respondents who thought that improvements in control were possible $(n=443)$ agreed on several suggestions to achieve this (Table 4).

Table 4. Suggestions for how asthma control could be improved made by those reporting scope for improvement

\section{Suggestion for improvement}

\begin{tabular}{|c|c|}
\hline & $\mathrm{n}=443^{*}$ \\
\hline Understanding which triggers to avoid & $52(230)$ \\
\hline $\begin{array}{l}\text { The ability to track when I have good and bad asthma days with equipment to help me understand what seems to } \\
\text { cause bad days }\end{array}$ & $32(142)$ \\
\hline Easier access to repeat prescriptions so I do not run out of medication & $30(134)$ \\
\hline My doctor/nurse providing me with better medication to control my symptoms & $28(123)$ \\
\hline Immediate access to help or support when my asthma deteriorates (e.g. advice helpline) & $26(115)$ \\
\hline More awareness of asthma amongst the general public & $25(111)$ \\
\hline Knowing how to use my medication more flexibly to manage my asthma & $24(107)$ \\
\hline More advice from my doctor/nurse on how to control my asthma & $22(97)$ \\
\hline $\begin{array}{l}\text { To discuss and develop an action plan with my doctor or nurse to help me understand how to control and reduce } \\
\text { my asthma symptoms }\end{array}$ & $19(83)$ \\
\hline More education available to me about asthma & $18(78)$ \\
\hline Being able to book frequent asthma reviews with my doctor & $18(79)$ \\
\hline Being able to spend more time with my healthcare professional talking about my asthma & $16(72)$ \\
\hline
\end{tabular}




\section{Table 5. Discussions between patients experiencing symptoms and healthcare professionals}

\begin{tabular}{|c|c|c|c|}
\hline \multicolumn{2}{|c|}{$\begin{array}{l}\text { Outcome of discussions in those with symptoms who } \\
\text { discussed them with their healthcare professional }(n=729)\end{array}$} & \multicolumn{2}{|c|}{$\begin{array}{l}\text { Reasons why those with symptoms did not discuss them with their } \\
\text { healthcare professional }(n=126)\end{array}$} \\
\hline Medication reviewed & $66(484)$ & Symptoms were not serious & $51(64)$ \\
\hline Inhaler technique checked & $63(459)$ & Asthma has impact regardless of discussing with doctor/nurse & $41(52)$ \\
\hline How to manage symptoms better & $43(316)$ & I have asthma and have to expect symptoms & $40(51)$ \\
\hline Agreed next time for a review & $41(300)$ & My doctor/nurse already does everything s/he can & $19(24)$ \\
\hline Impact of symptoms on life & $29(210)$ & Nothing done in the past & $15(19)$ \\
\hline Discussed action plan & $28(205)$ & Don't like to bother doctor/nurse & $13(17)$ \\
\hline Spacer technique checked & $27(200)$ & It is usually my fault for not taking medication properly & $9(11)$ \\
\hline Other & $7(54)$ & Could not make convenient appointment & $5(6)$ \\
\hline Not applicable/no outcome & $3(24)$ & Other & $10(12)$ \\
\hline
\end{tabular}

\section{Contact with HCPs involved in asthma management}

In all, $91 \%$ of respondents ( $n=983$ ) had asthma consultations in general practitioner (GP) surgeries, with a practice nurse $(69 \%)$ and/or a GP (60\%). Discussions about asthma symptoms with GPs occurred less than once a year (33\% of respondents), yearly (31\%), or every six months (20\%), while nurses were most commonly seen yearly $(50 \%)$ or every six months $(25 \%)$; only $15 \%$ of respondents saw a practice nurse less than once a year. The higher frequency of consultations with nurses may reflect the fact that nurses are often responsible for routine asthma reviews.

The majority of respondents $(78 \%, n=841)$ had been invited to an asthma review. However, $18 \%(n=200)$ of respondents stated they had never been invited ( $4 \%$ could not recall). Of those who had been invited for a review, $81 \%(n=684)$ stated they had always attended and $17 \%(n=147)$ had not always attended ( $1 \%$ could not recall). Overall, $32 \%(n / N=347 / 1,083)$ of respondents had therefore either never been invited to a review or had not always attended. Notably, $15 \%$ of respondents with frequent day-time symptoms and $14 \%$ of respondents with frequent night-time symptoms had not always attended reviews. For those respondents who did not always accept invitations $(n=147)$, the reasons selected included: the perception that asthma was well controlled (40\%); difficulty arranging a convenient appointment (29\%); no time for an appointment (23\%); the belief that their HCP was unable to do anything to improve their asthma (23\%); previous reviews had not been helpful (18\%). Of the 854 respondents who had experienced symptoms in the past two years, $85 \%$ had discussed their asthma with their HCP; these discussions most commonly covered medication review, inhaler technique, and symptom management (Table 5).

Overall, $28 \%(n=300)$ of respondents had discussed a personal asthma action plan (PAAP) with their HCP. Only $12 \%$ of all respondents were currently using a PAAP (Figure 3); $81 \%$ of these were involved in its development and $42 \%$ consulted it at least once a month. Most considered their PAAP to be 'very useful' (59\%, $n=76)$ or 'fairly useful' ( $31 \%, n=40)$. The most common reasons given by respondents for not discussing a PAAP with their HCP were unawareness that the plans were available $(56 \%, n=346)$ and the
Figure 3. Recall of discussions about a personal asthma action plan (PAAP). Values are given as $\%(n)$

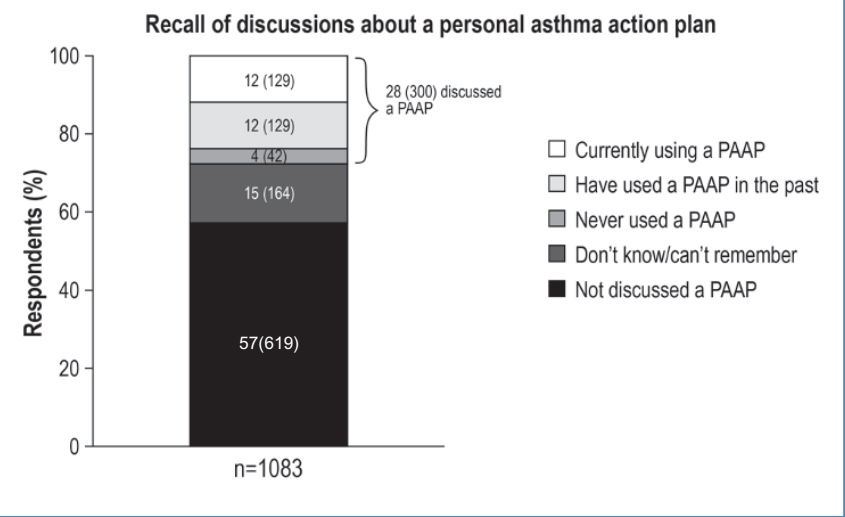

Figure 4. Responsibility for asthma control. The 'frequently' group included the answer options 'often (a few times a week)', 'sometimes (a few times a month)', and 'every day'. 'Rarely' was qualified as 'rarely (a few times a year)'. Values are given as $\%(n)$. Total answers for reliever use: $n=881$ (includes don't know: $n=2$ )

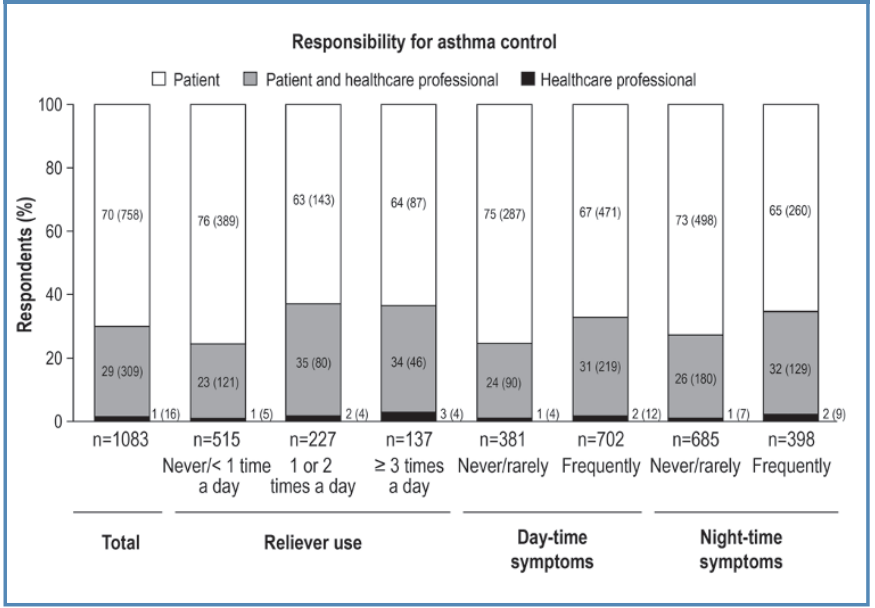




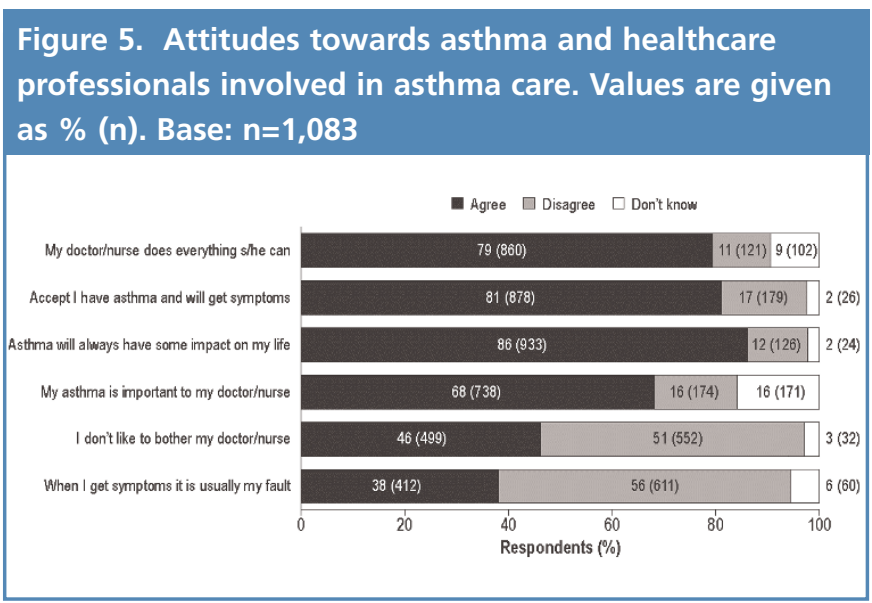

belief that their asthma was well controlled $(32 \%, n=201)$ or not serious enough ( $31 \%, \mathrm{n}=193)$.

Most respondents rated the relationship with their HCP as 'very good' $(45 \%, n=482)$ or 'good' $(32 \%, n=342)$. Respondents' feedback on how to improve the relationship included having a plan to improve asthma control $(16 \%, n=171)$, working together with the HCP (15\%, $n=165)$, and having more time for the consultation $(11 \%, n=120)$. However, 55\% $(n=592)$ thought that nothing could improve the relationship.

\section{Responsibility for asthma control}

Overall, $70 \%$ of respondents $(n=758)$ felt that they rather than their HCP had the 'main responsibility' for ensuring that their asthma was controlled; this proportion was similarly high in patients with frequent symptoms (Figure 4). In general, respondents accepted their symptoms and did not expect additional assistance from their HCP (Figure 5).

\section{Discussion}

\section{Main findings}

This comprehensive survey of patients with asthma in the UK shows that a significant discrepancy remains between patients' perceptions of asthma control and the symptoms that they experience. Although the majority of respondents believed that their asthma was controlled, many experienced frequent symptoms affecting their daily lives. Most respondents felt that they had a good relationship with their HCP; however, many patients thought that they had the main responsibility for managing their asthma and did not expect further help from their HCP. Moreover, while many respondents had been invited to a review, one in six of those who had been invited had not always attended. Only $12 \%$ of respondents said they currently used a PAAP; this was marginally higher than in a study of UK patients from 2007 (when it was reported as 8\%), indicating little improvement in recent years. ${ }^{26}$

\section{Strengths and limitations of the study}

This was a survey of over 1,000 asthma patients drawn from a large panel of the UK population. In contrast to clinical trials where up to $98 \%$ of patients may not meet the strict inclusion/exclusion criteria, ${ }^{27}$ this survey reflects the experiences of real-world patients, providing a basis for further research. As with all studies, this survey has limitations. Almost half of all respondents were aged 55 years or older; all data were directly reported by the respondents, who had previously stated that they had asthma. The screening question asked participants to confirm both the diagnosis and treatment of asthma to ensure that their answers related solely to this disease, hence the diagnosis was not independently confirmed. However, it is possible that some patients may have had chronic obstructive pulmonary disease (COPD), or COPD with asthma. In addition, some questions reflected the RCP '3 Questions', but the timescale (previous two years) was longer than that specified by the BTS/SIGN guidelines (the preceding month). ${ }^{12}$ In this survey, the longer timeframe was used to permit the capture of both a representative average of symptoms and rarer events.

\section{Interpretation of findings in relation to previously published work}

Our results provide a timely update on asthma in the UK, and highlight that little progress has been made in recent years in improving patients' knowledge and understanding of control. $15,18,28$ In a survey from 2004, $91 \%$ of patients with asthma from the UK regarded their asthma as under control even though two-thirds had symptoms at least two or three times a week. ${ }^{28}$ These findings are broadly similar to results from a recent European survey in which $91 \%$ of respondents perceived their asthma as controlled, even though $53 \%$ of these patients had awoken due to asthma in the week before the survey and $43 \%$ had required the use of oral steroids due to asthma in the previous year..$^{29}$ This discrepancy was consistently observed for the overall study population and for those within each country. ${ }^{30}$

Implications for future research, policy and practice The present study confirms that many patients with asthma have an impaired health-related quality of life and low expectations of improvement. Over $80 \%$ of respondents accepted that they would get symptoms and that asthma would have an impact on their life. Nonetheless, almost $60 \%$ thought that their asthma control could not be improved; there is clearly a need for more education and initiatives to raise patients' expectations.

Respondents' low expectations of achieving asthma control and the discrepancy between perceived control and symptoms may reflect misunderstandings regarding the term 'asthma control'. Some patients may consider good asthma crisis management - such as knowing what to do when they become symptomatic or have an attack - as being in control of their asthma. The asthma community may therefore want to reconsider the language used to define asthma control; as well as focusing on current symptoms, it may also be appropriate to consider the risk of asthma attacks. Patients can then assess this risk and make appropriate decisions.

Regular structured reviews can help improve asthma control. ${ }^{31}$ Reviews are one of the indicators in the Quality and Outcomes Framework (QOF) and National Institute for Health and Care Excellence standards used to assess the quality of primary care organisations and practices in the UK. ${ }^{32}$ Practices receive additional payments for achieving specified asthma management targets. This survey shows that asthma reviews often included an assessment of symptoms and inhaler technique, and discussions of a PAAP, in line 
with QOF requirements. However, contrary to BTS/SIGN and GINA recommendations, ${ }^{1,12}$ almost one in five respondents stated that they had never been invited to a review. Importantly, almost one in six of those respondents with frequent day-time or night-time symptoms had not always attended reviews. Indeed, many respondents saw an HCP about their asthma less than once a year; some patients may not attend reviews because they do not consider themselves 'sick' and want to maintain a healthy self-image. Also, this survey was conducted in a population that uses the internet, so it may be worthwhile to explore alternative ways of providing asthma reviews and information to patients. Indeed, these findings raise the issue of how to motivate patients to participate in reviews - especially those who may benefit from them the most. An alternative to face-to-face reviews could be telephone or online consultations. Telephone consultations are a cost-effective way to increase review rates, improve patients' confidence in managing their asthma, ${ }^{33}$ and target clinical care to those patients at high risk. ${ }^{34}$ By contrast, the evidence on the effectiveness of telecare is less clear. ${ }^{35}$

Asthma guidelines, including those from BTS/SIGN and GINA, recommend PAAPs for adults with persistent asthma. ${ }^{1,12}$ PAAPs improve adherence and asthma control ${ }^{36,37}$ and reduce emergency consultations. ${ }^{37}$ This survey confirmed the utility of PAAPs, with $90 \%$ of those using a plan describing it as useful; it was therefore disappointing that only $28 \%$ of respondents had discussed a PAAP with their HCP, and only $12 \%$ were currently using one. This shows little improvement from the 2004 UK survey, which found that $80 \%$ of patients had never been provided with a PAAP. ${ }^{28}$ Other studies have also highlighted the limited use of PAAPs. ${ }^{38-40}$

The recommended use of PAAPs reflects an increased emphasis on patients managing their own asthma, and a recent study suggests that many patients prefer an active or collaborative role. ${ }^{41,42}$ The low take-up of PAAPs and reviews in our survey population suggests that the sense of responsibility for asthma control may have shifted; only a small minority of respondents thought that their HCPs had the main responsibility for asthma care, and the majority did not expect additional assistance. In the past, HCPs may have been too prescriptive (preventing patients from taking a more active role), but the balance of responsibility may now have shifted too far towards the patient and away from the HCP. A more collaborative partnership focusing on patient-centred care would probably be optimal; this should include regular reviews and PAAPs to meet patients' need for information and support their self-management in the first few months after diagnosis. ${ }^{43-45}$ In clinical practice, it is important to assess asthma control regularly using a validated tool such as the ACQ, RCP '3 Questions', or $\mathrm{ACT}^{1,12}$ and to communicate the relevance and implications of these results to the patient. This will help patients understand how their current level of asthma control relates to their risk of exacerbations and what steps they can take to improve control.

\section{Conclusions}

This large survey highlights a continuing discrepancy between patient perception of asthma control and real-world symptoms. Most patients feel satisfied with their asthma treatment and have low expectations of improving their symptom control. Respondents generally feel that they have the main responsibility for their asthma management, despite having a good relationship with their HCPs. Our findings suggest a need to improve patients' understanding of the causes of poor asthma control and effective management of symptoms. It may be time for a radical rethink about how asthma is managed in primary care. Patients' needs and behaviours are continually changing, and personalised care (including regular asthma reviews and PAAPs) is more important than ever. Efforts should focus on understanding and removing the barriers to better asthma control, changing patients' beliefs and behaviours, and the importance of sharing responsibility for asthma management through an effective partnership between patients and HCPs. Achieving these aims will require continued education for both parties.

\section{Handling editor Björn Ställberg Statistical review Gopal Netuveli}

Acknowledgements The authors thank YouGov plc for conducting the survey on their behalf and Dr Diane Storey (DPS Ltd) and Dr Andreas Leidenroth (Oxford PharmaGenesis ${ }^{\top M}$ Ltd) for medical writing support. Emma Luck (Napp Pharmaceuticals Ltd) contributed valuable input to the study design, data acquisition, and data analysis. The authors take full responsibility for the content of the article.

Conflicts of interest The authors declare that they have no conflicts of interest in relation to this article.

Contributorship Both authors contributed to the conception and design of the study, interpretation of data, development of the flow, outline and content of the manuscript. Both authors critically revised each draft for content, approved the final version, accept responsibility for the final draft, and act as guarantors.

Funding The survey was funded by Napp Pharmaceuticals Ltd.

\section{References}

1. GINA Report, Global Strategy for Asthma Management and Prevention, 2011. http://www.ginasthma.org/uploads/users/files/GINA_Report_2011.pdf (accessed February 2011).

2. Masoli M, Fabian D, Holt S, Beasley R, Global Initiative for Asthma (GINA). The global burden of asthma: executive summary of the GINA Dissemination Committee report. Allergy 2004;59(5):469-78. http://dx.doi.org/10.1111/j.1398-9995.2004.00526.x.

3. The European Severe Asthma Survey, 2005. http://www.efanet.org/wpcontent/documents/SASSurveyFactSheet.pdf (accessed March 2013).

4. Asthma UK. Where do we stand? Asthma in the UK today, 2004 http://www.asthma.org.uk (accessed 2012).

5. Demoly P, Paggiaro P, Plaza $\mathrm{V}$, et al. Prevalence of asthma control among adults in France, Germany, Italy, Spain and the UK. Eur Respir Rev 2009;18(112):105-12. http://dx.doi.org/10.1183/09059180.00001209.

6. NICE support for commissioners and others using the quality standard for asthma, 2013. http://www.nice.org.uk/nicemedia/live/14080/62809/62809.pdf (accessed March 2013).

7. Pedersen S. From asthma severity to control: a shift in clinical practice. Prim Care Respir J 2010;19(1):3-9. http://dx.doi.org/10.4104/pcrj.2009.00059.

8. Department of Health. Confirmation of payment by results $(\mathrm{PbR})$ arrangements for 2012-2013. Tariff information spreadsheet. Admitted patient care and outpatient procedures. Asthma, 2012. http://dh.gov.uk/prod_consum_dh/groups/ dh_digitalassets/@dh/@en/documents/digitalasset/dh_133578.xls (accessed August 2012)

9. General Register Office for Scotland. Vital signs reference tables, 2010. http://www.gro-scotland.gov.uk/index.html (accessed August 2012).

10. NISRA. Deaths by cause. http://www.nisra.gov.uk/index.html (accessed August 2012)

11. Office for National Statistics. Mortality statistics: deaths registered in England and Wales (Series DR). http://www.ons.gov.uk/ons/index.html (accessed August 2012).

12. British Thoracic Society/Scottish Intercollegiate Guidelines Network. British guideline 
on the management of asthma. A national clinical guideline. Revised 2012. http://www.sign.ac.uk/guidelines/fulltext/101/index.html (accessed August 2012).

13. Reddel HK, Taylor DR, Bateman ED, et al. An official American Thoracic Society/European Respiratory Society statement: asthma control and exacerbations: standardizing endpoints for clinical asthma trials and clinical practice. Am J Respir Crit Care Med 2009;180(1):59-99. http://dx.doi.org/10.1164/rccm.200801-060ST.

14. Demoly P, Annunziata K, Gubba E, Adamek L. Repeated cross-sectional survey of patient-reported asthma control in Europe in the past 5 years. Eur Respir Rev 2012;21(123):66-74. http://dx.doi.org/10.1183/09059180.00008111.

15. Partridge MR, van der Molen T, Myrseth SE, Busse WW. Attitudes and actions of asthma patients on regular maintenance therapy: the INSPIRE study. BMC Pulm Med 2006;6:13. http://dx.doi.org/10.1186/1471-2466-6-13.

16. Cazzoletti L, Marcon A, Janson C, et al. Asthma control in Europe: a real-world evaluation based on an international population-based study. J Allergy Clin Immuno/ 2007;120(6):1360-7. http://dx.doi.org/10.1016/j.jaci.2007.09.019.

17. Partridge MR, Dal Negro RW, Olivieri D. Understanding patients with asthma and COPD: insights from a European study. Prim Care Respir J 2011;20(3):315-23. http://dx.doi.org/10.4104/pcrj.2011.00056.

18. Rabe KF, Adachi M, Lai CK, et al. Worldwide severity and control of asthma in children and adults: the global asthma insights and reality surveys. J Allergy Clin Immuno/ 2004;114(1):40-7. http://dx.doi.org/10.1016/j.jaci.2004.04.042.

19. Vermeire PA, Rabe KF, Soriano JB, Maier WC. Asthma control and differences in management practices across seven European countries. Respir Med 2002;96(3):142-9. http://dx.doi.org/10.1053/rmed.2001.1241.

20. Bellamy D, Harris T. Poor perceptions and expectations of asthma control: results of the International Control of Asthma Symptoms (ICAS) survey of patients and general practitioners. Prim Care Respir J 2005;14(5):252-8. http://dx.doi.org/10.1016/j.pcrj.2005.04.003

21. Canonica GW, Baena-Cagnani CE, Blaiss MS, Dahl R, Kaliner MA, Valovirta EJ. Unmet needs in asthma: Global Asthma Physician and Patient (GAPP) Survey: global adult findings. Allergy 2007;62(6):668-74. http://dx.doi.org/10.1111/j.1398-9995.2007.01352.x.

22. Colice GL, Ostrom NK, Geller DE et al. The CHOICE survey: high rates of persistent and uncontrolled asthma in the United States. Ann Allergy Asthma Immunol 2012;108(3):157-62. http://dx.doi.org/10.1016/j.anai.2011.12.017.

23. Chapman KR, Boulet LP, Rea RM, Franssen E. Suboptimal asthma control: prevalence, detection and consequences in general practice. Eur Respir J 2008;31(2):320-5. http://dx.doi.org/10.1183/09031936.00039707.

24. Long AA. The burden of asthma and improving patient outcomes. Am J Manag Care 2011;17(Suppl 3):S75-81. http://www.ncbi.nlm.nih.gov/pubmed/21761957.

25. British Healthcare Business Intelligence Association. Legal \& Ethical Guidelines for Healthcare Market Research, 2012. http://www.bhbia.org.uk/guidelines/ legalandethicalguidelines.aspx (accessed July 2013).

26. Haughney J, Fletcher M, Wolfe S, Ratcliffe J, Brice R, Partridge MR. Features of asthma management: quantifying the patient perspective. BMC Pulm Med 2007;7:16. http://dx.doi.org/10.1186/1471-2466-7-16.

27. Bjermer L. Evidence-based recommendations or "Show me the patients selected and I will tell you the results". Respir Med 2006;100(Suppl 1):S17-S21. http://dx.doi.org/10.1016/j.rmed.2006.03.023.

28. Haughney J, Barnes G, Partridge M, Cleland J. The Living \& Breathing Study: a study of patients' views of asthma and its treatment. Prim Care Respir J 2004;13(1):2835. http://dx.doi.org/10.1016/j.pcrj.2003.11.007.
29. Price D, Fletcher M, van der Molen T. Patients perceive their asthma to be controlled despite the presence of symptoms: a European survey of 8000 patients. Prim Care Respir J 2013;22(2):A1-A18. http://dx.doi.org/10.4104/pcrj.2013.00056.

30. Fletcher M, Price D, van der Molen T. Differences in asthma control and management in Europe. ERS 2013: 23rd Annual Congress of the European Respiratory Society, 2013, Barcelona, Spain.

31. Backer V, Bornemann M, Knudsen D, Ommen H. Scheduled asthma management in general practice generally improve asthma control in those who attend. Respir Med 2012;106(5):635-41. http://dx.doi.org/10.1016/j.rmed.2012.01.005.

32. National Health Service Employers. Quality and outcomes framework for 2012/13. http://www.nhsemployers.org/Aboutus/Publications/Pages/QOF_2012-13.aspx (accessed August 2012).

33. Pinnock H, Adlem L, Gaskin S, Harris J, Snellgrove C, Sheikh A. Accessibility, clinical effectiveness, and practice costs of providing a telephone option for routine asthma reviews: phase IV controlled implementation study. Br J Gen Pract 2007; 57(542):714-22.

34. Gruffydd-Jones K, Hollinghurst S, Ward S, Taylor G. Targeted routine asthma care in general practice using telephone triage. Br J Gen Pract 2005;55(521):918-23.

35. Ryan D, Price D, Musgrave SD, et al. Clinical and cost effectiveness of mobile phone supported self monitoring of asthma: multicentre randomised controlled trial. $B M J$ 2012;344:e1756. http://dx.doi.org/10.1136/bmj.e1756.

36. Bender BG, Long A, Parasuraman B, Tran ZV. Factors influencing patient decisions about the use of asthma controller medication. Ann Allergy Asthma Immunol 2007;98(4):322-8. http://dx.doi.org/10.1016/S1081-1206(10)60877-0

37. Kaya Z, Erkan F, Ozkan M, et al. Self-management plans for asthma control and predictors of patient compliance. J Asthma 2009;46(3):270-5. http://dx.doi.org/10.1080/02770900802647565.

38. Ring N, Malcolm C, Wyke S, et al. Promoting the use of Personal Asthma Action Plans: a systematic review. Prim Care Respir J 2007;16(5):271-83. http://dx.doi.org/10.3132/pcrj.2007.00049.

39. Ring $N$, Jepson R, Hoskins $G$ et al. Understanding what helps or hinders asthma action plan use: a systematic review and synthesis of the qualitative literature. Patient Educ Couns 2011;85(2):e131-43. http://dx.doi.org/10.1016/j.pec.2011.01.025.

40. Wiener-Ogilvie S, Pinnock H, Huby G, Sheikh A, Partridge MR, Gillies J. Do practices comply with key recommendations of the British asthma guideline? If not, why not? Prim Care Respir J 2007;16(6):369-77. http://dx.doi.org/10.3132/pcrj.2007.00074.

41. Caress AL, Beaver K, Luker K, Campbell M, Woodcock A. Involvement in treatment decisions: what do adults with asthma want and what do they get? Results of a cross sectional survey. Thorax 2005;60(3):199-205. http://dx.doi.org/10.1136/thx.2004.029041.

42. Plews $C$. Expert Patient Programme: managing patients with long-term conditions. Br J Nurs 2005;14(20):1086-9. http://www.ncbi.nlm.nih.gov/pubmed/16301939.

43. Newcomb PA, McGrath KW, Covington JK, Lazarus SC, Janson SL. Barriers to patient-clinician collaboration in asthma management: the patient experience. $J$ Asthma 2010;47(2):192-7. http://dx.doi.org/10.3109/02770900903486397.

44. Sarver N, Murphy K. Management of asthma: new approaches to establishing control. J Am Acad Nurse Pract 2009;21(1):54-65. http://dx.doi.org/10.1111/j.1745-7599.2008.00375.x.

45. Small M, Vickers A, Anderson P, Kay S. The patient-physician partnership in asthma: real-world observations associated with clinical and patient-reported outcomes. Adv Ther 2010;27(9):591-9. http://dx.doi.org/10.1007/s12325-010-0054-1.

Available online at http://www.thepcrj.org 